\title{
Identification and Localization of Nissl Bodies in Neurons of the Cervical Spinal Cord Segments of Grasscutters
}

\author{
Enemali $\mathrm{FU}^{1 *}$, Adebisi $\mathrm{SS}^{2}$, Ibegbu $\mathrm{AO}^{3}$, Buraimoh $\mathrm{AA}^{4}$ and Musa $\mathrm{SA}^{2}$ \\ ${ }^{1}$ Department of Anatomy, Faculty of Basic Medical sciences, Bingham University, Karu, Nasarawa State Nigeria \\ ${ }^{2}$ Department of Human Anatomy, Faculty of Basic Medical sciences, Ahmadu Bello University, Zaria, Kaduna State Nigeria \\ ${ }^{3}$ Department of Anatomy, Faculty of Basic Medical sciences, Federal University Abakiliki Ebonyi State Nigeria \\ ${ }^{4}$ Department of Anatomy, Faculty of Basic Medical Science, Kaduna state University, Kaduna, Kaduna State Nigeria
}

DOI: $10.36348 /$ sjmps.2019.v05i12.006 $\quad$ | Received: 25.11 .2019 | Accepted: 02.12.2019 | Published: 18.12 .2019

*Corresponding author: Enemali Felix U

\section{Abstract}

Grasscutters are currently being explored as laboratory models for scientific researches. The aim of the study was to Identify and localize Nissl bodies in neurons of the cervical spinal cord segments of grasscutters using cresyl fast violent (CFV) stains and to further measure the neuronal sizes of both anterior and posterior horns of the gray matter of the spinal cord. Six grasscutters comprising of three males and three females were utilized for the study. The studies were done using light microscopically methods. The animals were sacrificed by the method of decapitation and spinal cord was removed by splitting the vertebrae. The segments were fixed, processed, sectioned and stained with CFV for detailed studies of the spinal cord segments of the grasscutter. The result of the present study showed that the gray matter was stained dark purple due to the abundant presence of Nissl bodies in the neuronal cell bodies while the outer zone of white matter stained relatively lighter due to the presence of nerve fibers in the region. The result of the histometrical studies of cell areas in the anterior horn has the mean average of $2.56 \pm 0.13$ and the largest cell sizes of the cervical spinal cord was recordedin the anterior horn to be in $6.36 \pm 0.16$ while the posterior horn has the smallest cells with mean values of $3.86 \pm$ 0.24 . These findings can be useful in understanding the biology of the rodent.

Keywords: Grasscutter, spibal cord, Nissl bodies and histometrical studies.

Copyright @ 2019: This is an open-access article distributed under the terms of the Creative Commons Attribution license which permits unrestricted use, distribution, and reproduction in any medium for non-commercial use (NonCommercial, or CC-BY-NC) provided the original author and source are credited.

\section{INTRODUCTION}

Grasscutter is a wild herbivorous rodent found in the sub-Saharan region of Africa including Nigeria, Togo, Benin and Ghana. It is the biggest rodent after porcupine in the rodent family. It is referred to as African grasscutter, cane rat, cutting grass or grasscutter [1]. The body length of grasscutter (thryonomys swinderianus) varies from $25-70 \mathrm{~cm}$, with an average of $48 \mathrm{~cm}$ and their tail reaches $0.65-0.26 \mathrm{~cm}$ in length [1]. The total body weight of adult grasscutter ranges between $4-12 \mathrm{~kg}$. The heaviest body has an average weight of $4.5 \mathrm{~kg}$ in male grasscutter and $3.5 \mathrm{~kg}$ in female grasscutter [2], which looks like a giant guinea pig with a short tail. The body is heavily built, small round with bristle fur and coat and a circular ear [3] Most of the animals seen in the markets are males possibly because males lead the groups and are thus most prone to being trapped [4].

The spinal cord represents the most caudal part of the central nervous system. It is located within the canal of the vertebral column surrounded by cerebrospinal fluid [5]. It is composed of white matter and gray matter. The gray matter has neurons by which connections are made to other part of the nervous system and the body aat large. The soma of these neurons has Nissl bodies [6]. Nissl bodies are numerous microscopic clumps which are seen within the soma of the nerve cells or neurons. These structures consist of rough endoplasmic reticulum and associated ribosomal RNA. Nissl bodies are involved in protein synthesis and are prominence in the nerve cells that are metabolically active [7]. The aim of this study was to provide information on the localization and distributions of Nissl bodies in different neurons in the cervical segments of the spinal cord of the grasscutter.

\section{MATERIALS AND METHODS}

Animals Procurement and Management

Six (6) grasscutters (thryonomys swinderianus) made up of three males and three females were utilized for the study. The animals were procured from Tamqua 
farm in Zaria, Kaduna State and the animals were housed in the animal house of the Department of Anatomy Ahmadu Bello University, Zaria. Ethical permission was obtained from $\mathrm{ABU}$ Committee on Animal Use and Care (ABUCAUC) Ahmadu Bello University, Zaria.

Animals were fed with sugar cane and elephant grass and water was allowed ad-libitum.

\begin{abstract}
Animal sacrifice
Grasscutters were anaesthetized and sacrificed. After which the skin and epaxial muscles were dissected to expose the vertebral spine and the spinal cord were harvested by splitting the vertebral column. This was according to the method of Olude et al. [8]. Spinal cord segments were identified and dissected per animal based on the methods described by Farag et al. [9]. The gross features of the cervical spinal cord are shown in figure 1 below. The cervical spinal cord segments of grasscutter were fixed in Bouin's fluid in different tissue sample containers for 24 hours. After fixating the tissues in Bouin's fluid, the spinal cord tissues were removed from the fixative and the spinal cord tissues were passed through a process of dehydration in ascending grades of alcohol (ethanol) namely; 70\%, 80\%, 95\% and absolute alcohol (100\%) for two changes each. Each of the chages lasted for 2 hours. The tissues were then cleared in xylene and embedded in paraffin wax. Serial sections were made using a rotary microtome. The tissue sections were deparaffinised and rehydrated two changes of absolute alcohol for $3 \mathrm{~min}$ each change and the tissues were stained in $0.1 \%$ Cresyl violet for $15 \mathrm{~min}$. The tissues were quickly rinsed in tap water to remove excess stain. After raising the tissues in tap water, the spinal cord tissues were washed in $70 \%$ ethanol to remove the stain. The spinal cord sections were immersed for two minutes in differentiation solution and staining was checked on the microscope.
\end{abstract}

Spinal cord tissues were dehydrated through changes of absolute ethanol andcleared in xylene. After which the tissues were mounted and were allowed to dry. The stained spinal cord sections were examined for Nissl bodies under the light microscope fitted with a digital camera and connected to a laptop. The stained sections were examined under the binocular light Olympus microscope (HM-LUX Leitz Wetzlar Germany) at different magnifications. The binocular light Olympus microscope (HM-LUX,Leitz Wetzlar, Germany) was fitted with a digital camera and a computer with imaging software (AmScope MT version 3.0.0.5 USA) according to the manufacturer 110 instructions. Histological slides were studied for Nissl bodies (Nissl substances) and photomicrographs of the tissues were taken at different magnifications

\section{Histometrical studies}

The histometry was done using the light microscope with a $\times 40$ objective $(\times 400$ magnification) and computer running image processing (AmScope MT version 3.0.0.5, USA) for microscopy. Digital micrographs which were microscopic images of the spinal cord (CFV stain) were captured and calibrations of software for measurement of microscopic features on 112 the micrographs of spinal cord which were stained with crestyl fast violent stain were conducted.

The process of calibrations involved the following steps; Firstly, a micrometer slide ( that is containing the spinal cord tissue) come as $1 \mathrm{~mm}$ graduated in $0.01 \mathrm{~mm}$ unit (that is divided $10 \times$ into 100 um unit) was captured at the same magnification and quality (pixels) the micrograph of the spinal cord was photographed. Secondly, the line tool was selected and was carefully measure from start of one major line of the micrographs of spinal cord of Grasscutter from end to end. Recorded length in pixels; in this study was 649 pixels/100um, $6.49 \mathrm{pixel} / \mathrm{um}$. Next, the polygon tool was used to measure the area and perimeter of the desired neurons of the various spinal cord segments of Grasscutter. Values of the measurements were computed and presented automatically by the software. Plate II below is showing the summary of the process of histomerty that was used in this study.

\section{DATA ANALYSIS}

Data on areas and perimeter of neurons were taken and alculated and expressed as mean \pm standard error of mean, work on data was done using SPSS version 20.0

\section{RESULT}

\section{Histometrical studies}

The neuronal morphological characteristics of the neurons of the cervical spinal cord segments of spinal cord of grasscutters for neuronal area and neuronal sizes were being evaluated. The mean values and SEM for neurons of the cervical spinal cord cord segments for cell area (A), cell perimeter (cell size) (P) showed that the value for mean and SEM for cell perimeter of the cervical anterior horn $\mathrm{CVH}(\mathrm{P})$ and neuronal area (A) were calculated to be $6.36 \pm 0.16$ and $2.56 \pm 0.13$ respectively while for cell perimeter of the cervical posterior horn $\mathrm{CDV}(\mathrm{P})$ and neuronal area $(\mathrm{A})$ were calculated to be $3.86 \pm 0.24$ and $0.83 \pm 0.09$ as shown in table 1 below. 
Table-I: Parameters of neuronal cells in cervical spinal cord segments of grasscutter showing minimum, maximum and mean values

\begin{tabular}{|l|l|l|l|}
\hline Variables & Minimum Value & Maximum Value & Mean \pm SEM \\
\hline CVH A & 1.65 & 3.71 & $2.56 \pm 0.13$ \\
\hline CVH P & 5.05 & 8.08 & $6.36 \pm 0.16$ \\
\hline CDH A & 0.51 & 1.40 & $0.83 \pm 0.09$ \\
\hline CDH P & 2.91 & 5.07 & $3.86 \pm 0.24$ \\
\hline
\end{tabular}

Descriptive statistics of the values of cell area (A) $\left(\mu \mathrm{m}^{2}\right)$ cell perimeter (cell size), $(\mathrm{P})(\mu \mathrm{m})$ anterior horn of cervical spinal cord segment $(\mathrm{CVH})$ and posterior horn of cervical spinal cord segment $(\mathrm{CDH})$.

\section{Nissl studies}

The transverse sections of cervical spinal cord segments stained with crestyl fast violent (CFV) showed two distinct regions and a central lumen (central canal). The outer region was lighterly stained while the inner region which is the gray matter was deeply stained dark purple this patternwas seen throughout the various segments of cervical spinal cord cervical (Figure 2).

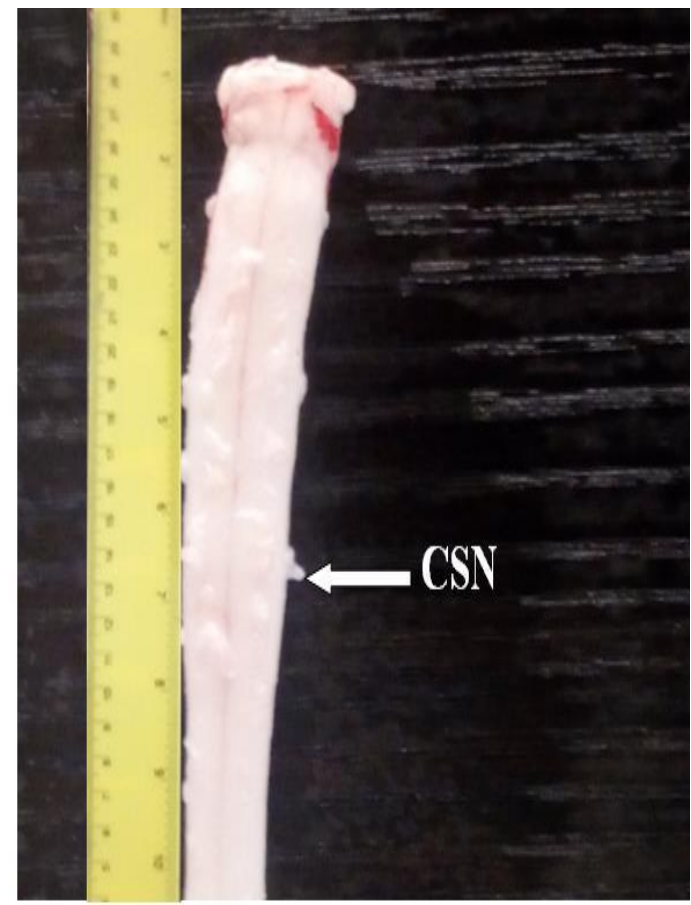

Fig-1: The gross features of the cervical spinal cord segments of grasscutter with the cervical spinal nerve (CSN)
At higher magnification the result showed Nissl substances in the soma of the neurons of the spinal cord of grasscutter as shown in figure 3(I-VIII).

The presence of Nissl substances were seen in the soma of the multipolar neurons of the anterior horn of cervical spinal cord segment (figure 3). The posterior horns cells of the spinal cord segments of grasscutter were observed to also contain Nissl substances within their soma as shown in figure 3(I-VIII).

The result also showed the white matter of the spinal cord segments was observed to be free of Nissl substances (figure 2). The central canal was seen in the central core of the gray matter as a lumen which run throughout the length of the spinal cord of the Grasscutter as shown in figure 2.

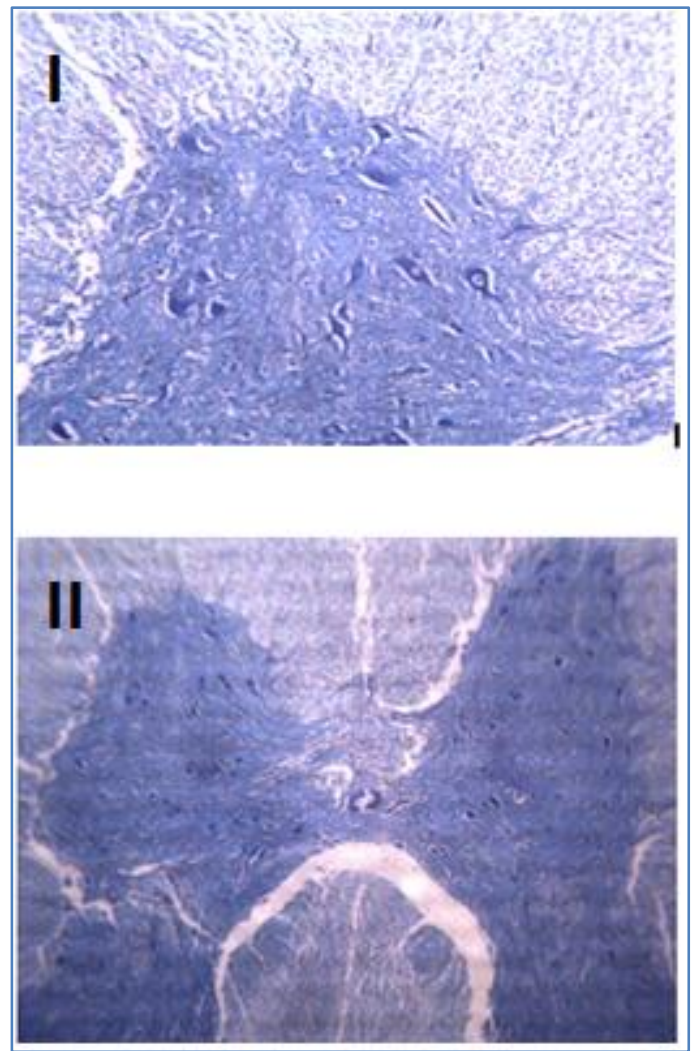

Fig-2 (I-II): Microscopic anatomy of the cervical spinal segment at the level of $C_{7}$. The spinal cord has two regions gray matter $(G)$ and white matter $(W)$. The central canal $(C)$ runs the entire cervical region of the spinal cord, the white matter $(\mathrm{W})$ stained lighter than the gray matter $(G)$ which has anterior $(A)$ and posterior horns (P) CFV stain X100 


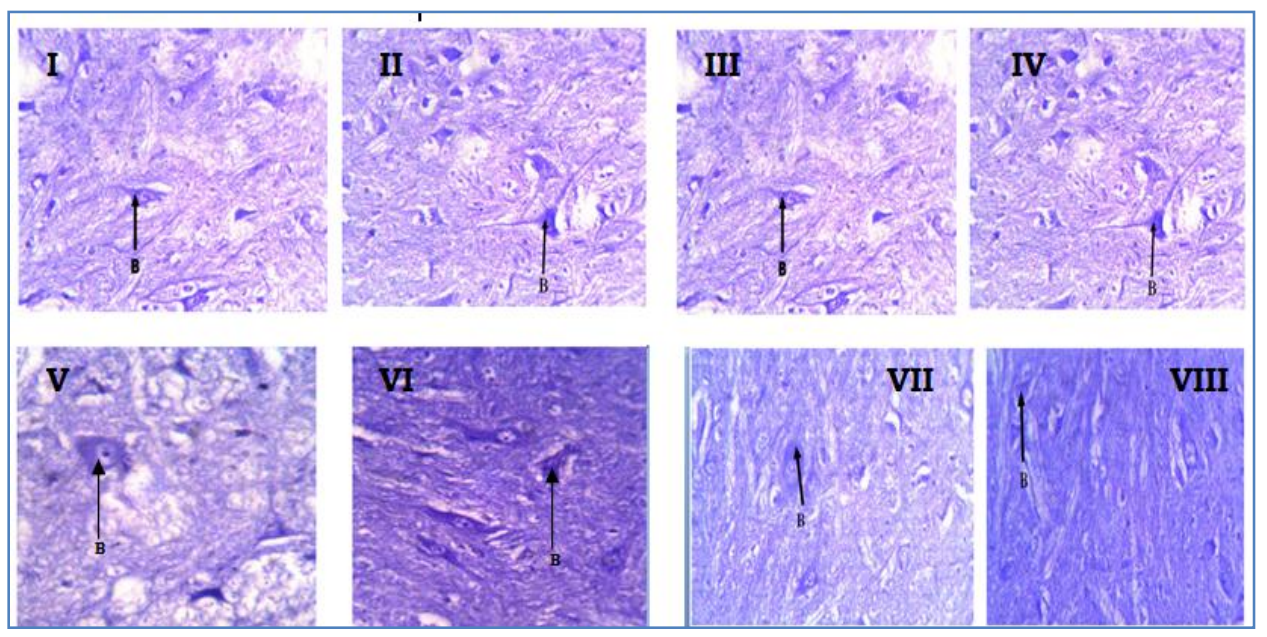

Fig-3 (I-VIII): Sections of the spinal cord segments of grasscutter at different cervical spinal cord levels. Section I is showing the anterior horn of cervical spinal cord segment at $C_{2}$. Section II is showing the posterior horn of cervical spinal cord segment at $C_{2}$, section III is showing the posterior horn of cervical spinal cord segments at $C_{4}$ section IV is showing the anterior horn of cervical spinal cord segment at $C_{4}$ section $V$ is showing the anterior horn of cervical spinal cord segments at $\mathrm{C}_{5}$. Section $\mathrm{VI}$ is showing the posterior horn of cervical spinal cord segments at $\mathbf{C}_{5 .}$. Section VII is showing the posterior horn of cervical spinal cord segments at $\mathbf{C}_{7}$. Section VIII is showing the anterior horn of cervical spinal cord segments at $C_{7 .}$. Arrows are showing the presence of Nissl bodies $(B)$ in the cervical spinal cord segments of grasscutter. CFV stain X250

\section{DISCUSSION}

The result of the Nissl study showed inner gray matter of the spinal cord of grasscutter which stained dark purple due to the abundant presence of Nissl substances in the neuronal cell bodies while the outer zone of white matter stained relatively lighter due to scanty neuronal cell bodies in the region. These findings are in agreements with the findings in other rodents [10].

The cells in the anterior gray hornsof the cervical spinal cord of Grasscutter are multipolar motor neurons. Their cytoplasms are characterized by a prominent vesicular nucleus, a distinct nucleolus and coarse clumps of basophilic material, the Nissl bodies. The Nissl substances extend into the dendrites but not into the axons of neurons of the spinal cord of Grasscutter. These findings are in agreement with the findings in the Wistar rat [11] and in horse [12, 13] and sheep [14] and donkey [15].

Nissl bodies have been reported to play key roles in cellular metabolism [16]. These ribosomes had been found in large amounts in the cytoplasm of neurons as cytoplasmic riboxyribonucleic acid under the control of nuclear deoxyribonucleic acid (DNA), cytoplasmic RNA is concerned with protein synthesis.

The presence of Nissl bodies in the neurons of cervical spinal cord segments of of Grasscutter could be responsible for the synthesis of protein molecules that are essential for the transmission of nerve impulses between neurons.

Nissl bodies also serve to maintain nerve fibers. The synthesized proteins travel along the dendrites and replace proteins that are destroyed in cellular activity. Subsequently, the surplus proteins that produce Nissl bodies are transmitted to the Golgi apparatus. There they are stored temporarily and to some are added carbohydrates [17].

The anterior horn cells of the spinal cord segments' of grasscuuter contain Nissl substances. The progressive selective staining of the Nissl substance produces an extremely clear and characteristic cellular picture in the spinal cord of grasscutter which is of fundamental importance in neurocytology, since it furnishes the most delicate and accurate criterion for the wellbeing of the neurons as well as providing information for any deviationfrom the normal healthy state of the neurons. Series of studies have shown that the material from which the Nissl substances are elaborated areformed primarily round the nucleolus inside the nucleus and migrates towards the periphery of the nucleus, and then diffuses gradually through the nuclear membrane to form Nissl bodies in the cytoplasm [18].

The elegant study by Guillery [19] of the fine structure of mammalian neurons has conditioned the expectation that Nissl bodies everywhere will be found to consist of more or less ordered and compact arrays of granulated endoplasmic reticulum. The structure of Nissl bodies consists of a granular and concentrated section of the endoplasmic reticulum. Nissl bodies are essential to the well-being of a neuron; a decrease in the number of Nissl bodies in a neuron indicates neural degeneration [10]. Nissl body structures change abruptly in the case of inflammatory disease, oxygen deprivation or trauma to the nervous system[20]. Nissl bodies can change and even dissolve and disappear. As in the conclusion of the chromatolysis [15]. In the animal kingdoms, a positive correlation exists between the size of a cell and its Nissl bodies content. Spinal motor neurons of the anterior horn cells are among the 
largest mononucleate cells in animals, they can be suspected to have more Nissl bodies in their soma than prosterior horn cells of the spinal cord of Grasscuuter which are smaller in size [21].

Furthermore, Nissl bodies help to maintain motor neuronal size and shape. Therefore the presence of Nissl bodies in the spinal cord of Grasscutter contributes to the shapes and sizes of neurons in the spinal cord of grasscutter.

In this study, cell area, cell perimeter (cell size) of neurons in cervical, cord regions of the grasscutters. The descriptive statistics showed that the greatest mean value for cell perimeter and cell area was calculated in the anterior horn while the least values cell perimeters and cell areas were calculated in the posterior horn of the cervical spinal cord region of the spinal cord of Grasscutter. Find similar to findings in other mammals [22]. these findings suggest that the cells of the ventral horns of the spinal cord of grasscutter were generally larger than those of the posterior horns of the spinal cord segments of grasscutter the presences of large cells in the ventral horn of the cervical spinal cord segment also suggest the posterior horns of rhe cervical region are welled developed and could explain fore limbs efficiency The anterior horns contains the cell bodies of motor neurons that send axons through the anterior roots of the spinal nerves to terminate on striated muscles.

It has been shown that the grasscutter possesses good motor coordination and well-developed fore limbs [18, 23].

\section{CONCLUSION}

The presence of Nissl bodies in the cervical spinal cord segments of grasscutter suggest that the neurons of the cervical spinal cord segments in this study were active in protein synthesis while the histometrical studies established that the cell size of the anterior horn neurons were larger than that of the posterior horn neurons.

\section{REFERENCES}

1. Agwunobi, L. N., Ajuobi, V. I., \& Wogar, G.I. (2009). The performance of Grasscutter (Thryonomys swinderianuss) on diets containing varying levels of crude fibre Procurement Nigeria Society. Tropical Animal Health Production, 21: 103-119

2. Merwe, M. (2000). Tooth succession in the greater cane rat Thryonomys swinderianus. Journal of Zoology, 251: 541-545

3. Akinloye, A.P. (2005). Update on Grasscutter Rearing-Thryonomys Swinderianus (Temminck). Height Mark Printers, Ibadan, Nigeria, 21-23.

4. Aluko, F. A. (2014). Qualitative characteristics of Thryonomys swinderianus swinderianus and
Thryonomys swinderianus gregorianus. Nigerian Journal Animal Production, 41(1): 258-263.

5. Amene, S., Nima, R. (2017). The role of timing in the treatment of spinal cord injury. Biomedicine and Pharmacological therapy, 92: 128-139.

6. Silva, N.A., Sousa, N., Reis., R.L. and Salgado, A. (2014). "From basics to clinical: A Comprehensive rehensive review on spinal cord injury". Progressive Researches in Neurobiology, 114: 2557.

7. Adjene, J.O. \& Igbigb, P.S. (2014). Effects of Chronic Administration of Efavirenzon the Nissl Substances on the Intracranial Visual Relaycentres of Adult Wistar Rats. Anatomy Journal of Africa, 80(4): 101-115

8. Olude, M.A., Idowu, A.O., Mustapha, O.A., Olopade, J. O., \& Akinloye, A.K. (2015). Spinal Cord Studies in the African Giant Rat (Cricetomys gambianus, Waterhouse). Nigeria Journal of Physiological Science, 30(1-2): 25-32.

9. Farag, F., Elayat, M., Wally, Y. and Elkarmoty, A. (2012). Morphometric Studies on the Spinal cord Segments of the Domestic Rabbit (Oryctolagus cuniculus). Journal of Veterinary Anatomy. 5(2): 33-47.

10. Dellmann, H.D., \& McClure, R.C. (1975). Central Nervous System of Domestic Animals in "SissonGrossman" Anatomy of Domestic Animals. 5th edition, $2 ; 302$

11. Humberto, M., \& Antonio, I. (2015). Microvascular Dysfunction after Spinal Cord Injury. Endothelial Cell Plasticity in the Normal and Injured Central Nervous System, Journal Neurophysiololgy, 67; 153-161.

12. Bolat D. S., Bahar, E. Sur, M. L., \& Selcuk, S. (2012). Tipirdamaz, Selective gray and white matter staining of the horse spinal cord. Kafkas Universitesi Veteriner Fakultesi Dergisi, 18 (2): 249-254.

13. Bahar, S., Bolat, D. and Selcuk, M. (2013). The Segmental Morphometric Properties of the Horse cervical Spinal Cord: A Study of Cadaver. The Scientific World Journal, 3(4): 1155-734923.

14. Done, J., Woolley, J., Barnard, V., Upcott, D., \& Hebert, C. (1985). Border disease of sheep: Spinal cord morphometry, Journal of Comprehensive Pathology, 95, 325-333

15. Hifny, A., Hemmoda, A.S., \& Berg, R. (1984). Anatomical studies on the cerebellum of the donkey of egypt. Gegenbaurs Morphology Jahrb, 130, 707-717

16. Dyce, K.M., Sack. W.O., \& Wensing, C.G. (2010). Textbook of Veterinary Anatomy. (Philadelphia, $\mathrm{Pa}$ London: Saunders Comprehensive, 279-90.

17. Fix, J.D. (2008). Basal Ganglia and the Striatal Motor System. NeuroAnatomy (Board Review Series) (4th ed.). Baltimore: Wulters Kluwer and Lippincott Wiliams \& Wilkins, 274-281. 
18. Kingdom, J. (1974). East Africa Mammals (Hares and Rodents). Volume. 11. Academic Press, London

19. Guillery, R. W. (2005). Observations of synaptic structure: Origins of the neuron doctrine and its current status. Philosophical Transactions of the Royal Society B: Biological Sciences, 1458; 12811307.

20. Lima, F.C., Santos, A.L.Q., Lima, B.C., Vieira, L.G., \& Hirano, L.Q.L. (2010).Topographic Anatomyof the spinal cord: vertebromedullary relationships in Mazama gouazoubira. Acta Scientiarum Biolological Sciences, 32 89-194.
21. López-Muñoz, F., Boya, J., \& Alamo, C. (2006). Neuron theory, the cornerstone of neuroscience, on the centenary of the Nobel Prize award to Santiago Ramón y Cajal. Brain Research Bulletin, 70 (4-6): 391-405

22. Junqueira, J., Carneiro, F., Tecido nervosa, In: Junqueira, J, Carneiro, F. (2013). Histologia Básica: Texto and Atlas. 12th ed. Rio de Janeiro: Guanabara Koogan, 149-175.

23. Llinás, S., \& Rodolfo, R. (2014). Intrinsic electrical properties of mammalian neurons and CNS function: a historical perspective. Frontiers in Cellular Neuroscience, 8: 320. 